\title{
Erratum to: Sirenomelia: a review on embryogenic environmental theories, novel three-dimensional ultrasound imaging and first trimester diagnosis in a case of mosaic $69, \mathrm{XXX} / 46, \mathrm{XX}$ fetus
}

\author{
Gabriele Tonni • Gianpaolo Grisolia
}

Published online: 25 May 2013

(C) Springer-Verlag Berlin Heidelberg 2013

Erratum to: Arch Gynecol Obstet

DOI 10.1007/s00404-013-2847-3

Unfortunately, there is a swap between first and family name of author group in the published article. The correct author group is given below.

Gabriele Tonni · Gianpaolo Grisolia

The online version of the original article can be found under doi:10.1007/s00404-013-2847-3.

G. Tonni (凹)

Department of Obstetrics and Gynecology, Prenatal Diagnostic Center, Guastalla Civil Hospital, ASL Reggio Emilia, Via Donatori Sangue, 2, 42016 Guastalla Reggio Emilia, Italy e-mail: tonni.gabriele@ausl.re.it

G. Grisolia

Department of Obstetrics and Gynecology, Prenatal Diagnostic

Center, Carlo Poma Hospital, Mantua, Italy 